\title{
EI Boticario del Siglo XVIII ante la inquisición
} The 18th-century Apothecary before the Inquisition

\author{
Marisa Mundina García \\ Master Historia de la Ciencia, UAB, España (marisa.mundina@gmail.com)
}

Recibido el 11 de julio de 2018; revisado el 30 de julio de 2018; aceptado el 29 de agosto de 2018; publicado el 13 de septiembre de 2018

RESUMEN: Las fuerzas vivas, según Leibnitz (s. XVII), son aquellas fuerzas que producen movimiento y cambio frente a las fuerzas muertas, que no lo producen. Posteriormente, esta misma expresión se aplicó a las personas influyentes de un lugar que actúan en beneficio del mismo: el alcalde, el maestro, el cura y el boticario eran las fuerzas vivas en los pueblos y barrios de ciudades del siglo XVIII. Sus opiniones eran consideradas y muchas veces aceptadas ciegamente por la colectividad. En este trabajo se pretende ver cuál era la posición del boticario del XVIII ante la Inquisición y la fe católica y la influencia de la Ilustración en esta postura.

PALABRAS CLAVE: Boticario, Inquisición, Ilustración, proposiciones.

\begin{abstract}
The living forces, according to Leibnitz (17th century), are those forces that produce movement and change in the face of dead forces, which do not produce it. Subsequently, this same expression was applied to the influential people of a place that act for the benefit of the same: the mayor, the teacher, the priest and the apothecary were the living forces in the towns and neighborhoods of eighteenth-century cities. Their opinions were considered and often blindly accepted by the community. In this work we try to see what was the position of the apothecary of the XVIII before the Inquisition and the Catholic faith and the influence of the Enlightenment in this position.
\end{abstract}

KEYWORDS: Apothecary, Inquisition, Illustration, propositions. 


\section{Introducción}

El siglo XVIII es el siglo del pensamiento ilustrado, de la supremacía de la razón por encima de la superstición. Así para los ilustrados la razón era el instrumento esencial para alcanzar la verdad, por lo que debían ser sometidas a crítica todas las creencias admitidas heredadas de la tradición, especialmente aquéllas que se basaban en los prejuicios, en la ignorancia y en la superstición o en los dogmas religiosos (Mestre \& Pérez García, 2004). En España es un siglo complicado, la guerra de Sucesión y el subsiguiente reformismo borbónico cambiarán las bases del país. Las ideas ilustradas llegarán poco a poco y se limitarán a una minoría culta de élite, ya que la aristocracia, el clero y el pueblo llano continuarán aferrados a los valores tradicionales, especialmente a la religión. Destacará, entre otras, la figura del boticario, respetado, culto y con buen estatus social; en su rebotica, sobre todo en las farmacias de pueblo, se reunían las fuerzas vivas del lugar en tertulias con el médico, el alcalde, quizás el cura, para comentar las noticias de actualidad, las necesidades de la población (Urreiztieta, 1985); en las de grandes ciudades, se crearán sociedades o academias como la de Ciencias de Barcelona, fundada en la rebotica de Francisco Sala, etc. Por ello, resulta interesante ver qué opinión tenía este estamento de una institución que tuvo tanta influencia entre la población española como la Inquisición, y cómo influyó ésta en la profesión de boticario. Como dijo Enrique Tierno Galván, entre ruido de morteros y tintineo de probetas, se hizo parte de la historia de España contemporánea.

\section{La farmacia ilustrada}

En la farmacia ilustrada, encontramos todavía los remedios procedentes del galenismo y de la iatroquímica ${ }^{1}$, que le va ganando terreno (Calleja, 1992). Los primeros, siguiendo la tradición de Hipócrates, sostenían que la enfermedad se debía al desequilibrio de los humores de los que se componía el organismo humano. Para corregirlo, se debía expulsar el humor sobrante aplicando sangrías, purgas, diuréticos, etc. que se aplicaban inespecíficamente a cualquier tipo de enfermedad. En cambio, los iatroquímicos o paracelsistas ${ }^{2}$ creían en que cualquier realidad se componía de tres elementos: el mercurio, el sulfuro y las sales que se combinaban entre ellos formando nuevos elementos y destacando la presencia del arqueo, un principio vital que les da su especificidad. Paracelso cree que la enfermedad se debe a influencias cósmicas, divinas, sustancias tóxicas, causas

\footnotetext{
${ }^{1}$ Iatroquímica: busca explicaciones químicas a los procesos patológicos y fisiológicos del cuerpo humano, y proporciona tratamientos con sustancias químicas.

${ }^{2}$ El principal impulsor de la iatroquímica fue Paracelso, s. XVI.
} 
naturales y motivos espirituales o psíquicos, rechazando la patología humoral galénica entonces dominante.

Así, la curación va encaminada a eliminar la sustancia ajena al organismo que produce la enfermedad. Primero debemos identificar el germen y luego, para que el arqueo recupere el control del organismo eliminando el germen, debemos medicar con sustancias químicas como el antimonio, el opio, el arsénico, las sales de plomo, el cloruro de hierro, etc. de forma específica para cada tipo de germen y en su justa y apropiada dosis (Rodríguez Sánchez, 2008). Continuarán llegando nuevos remedios de América como el guayaco para curar la sífilis, que se extendía entre la sociedad europea y la americana también. Empiezan a aparecer nuevas teorías que cambiarán el concepto de enfermedad y sus medios de curación, aparecen los inicios del higienismo, que se basará en la teoría miasmática de propagación de las enfermedades y, como consecuencia, las primeras teorías sociales sobre la enfermedad: el hacinamiento y las malas condiciones higiénicas en que vivía la población, favorecía la propagación de los miasmas y, por tanto, de las enfermedades que deberán ser controladas por otros canales, no solo los medicamentos sino también la Sanidad Pública y la medicina social, en definitiva. Ya en el siglo XIX, con el descubrimiento de los microorganismos y las primeras leyes de la genética, aparecerá el paradigma biologicista ${ }^{3}$ de la enfermedad, desaparecerán los conceptos mágicos, los naturalistas y los miasmáticos. La preparación al paso a este nuevo paradigma se da con la aparición de la vacuna antivariólica de Jenner, los antisépticos, los analgésicos, los anestésicos y los alcaloides. La farmacia dejará la tradición escolástica e iatroquímica, dejará de ser barroca, y se hará racional y científica, más segura y eficaz, aunque también más aburrida, privada de las aportaciones de autores que idearon atrevidas teorías y defendieron el uso de remedios singulares como el agua, la música o el agua de alquitrán para conseguir la inexistente panacea que cure todas las enfermedades (Esteva De Sagrera, 2007).

\section{El boticario}

En la Ilustración, la profesión farmacéutica en España por los primeros años del siglo XVIII, según F. Javier Puerto, se caracteriza por su descentralización, falta de uniformidad e ineficacia institucional. Los Borbones tratarán de corregir todo esto con la instauración del Real Tribunal del Protomedicato, de origen castellano y controlado por médicos (Puerto Sarmiento, 1992). No varió la consideración social del boticario, reflejada en la disposición otorgada por Felipe IV en 1650 y

\footnotetext{
${ }^{3}$ Entiende la enfermedad como el estado producido por un error en un mecanismo o proceso biológico frente al mágico, por ejemplo.
} 
confirmada por los sucesivos soberanos, por la que se declaraba a la farmacia «arte científica en todo igual a la medicina» y que les liberaba del pago de los cientos y de las alcabalas en «lo relativo a los compuestos que venden en sus boticas», de la obligación de alojar soldados, de la asistencia de bagajes y de las cargas concejiles, aunque no de los otros impuestos y gravámenes que hubieran de satisfacer como ciudadanos; dicho en otras palabras, les separaba de la consideración de los oficios artesanos y les asimilaba a las artes liberales (Puerto Sarmiento, 1992). Sin embargo, el control provincial pasaba a manos de la Corte y el boticario volvía a depender del médico. No será hasta finales de siglo que consiga su ansiada independencia, cuando Carlos III divida el Protomedicato en tres audiencias independientes correspondientes a la Medicina, la Cirugía y la Farmacia. El proceso de aprendizaje no variará demasiado: las ordinaciones municipales de 27 de noviembre de 1433 ya obligaban tanto a la superación de un examen, previa práctica de ocho años, como al reconocimiento de las drogas, tanto simples como compuestas. Todo ello en manos de un metge e un mercader droguer e dos specim, acompañados en la visita por el Mostassaf de la ciudad (Zarzoso, 1996). La enseñanza de la farmacia no cambiará sustancialmente hasta la segunda mitad del siglo XVIII, y continuará en poder de los gremios: para ser recibidos a examen, los boticarios debían presentar fe de bautismo, información de limpieza de sangre y certificado de haber trabajado cuatro años con un maestro aprobado, quien debía emitir un informe sobre su capacidad (Zarzoso, 1996). De hecho, existen casos de inhabilitación del ejercicio de la profesión por el Tribunal desde el siglo XVI, es el caso de Diego de Cáceres, de Oropesa en el año 1547 (Proceso de fe de Diego de Cáceres), que es inhabilitado por morir sus abuelos como judíos y ser sus padres cristianos nuevos. Ya en el siglo que estudiamos, Antonio Rodríguez Valderrama (Proceso de fe de Antonio Rodríguez Valderrama) es investigado por el Santo Oficio sevillano cuando intenta acceder al cargo de familiar de la Inquisición por ser hijo de judíos, cosa que esconde tras el pseudónimo de Antonio Gerónimo Marcos Rodríguez Alariz y Soriano. Sus padres y hermana, según los boticarios gaditanos que le impidieron ejercer su profesión por no tener certificado de limpieza de sangre, fueron reconciliados en auto de fe en Granada en el año 1726. La necesidad de presentar una genealogía que demostrara la ausencia de ascendencia judía para ejercer la profesión de boticario se mantendrá hasta el año 1833 en que la Junta Superior Gubernativa de Farmacia, establecida por los Borbones levantará este veto (Puerto Sarmiento, 1992).

En los pueblos, como ya hemos dicho, el boticario era una figura muy bien considerada socialmente hablando. Martín Verdejo estudió la figura de Bernabé García, un boticario rural con aspiraciones de hidalguía, del Toledo del XVIII. Durante su etapa como boticario (1696-1710) llegará a ser regidor de la villa en 1700 y alcalde ordinario en 1703; además, destaca por su 
mecenazgo artístico en la iglesia: financió el retablo mayor de la iglesia, y la capilla de San Antonio de Padua. Por otra parte, en una época en que el analfabetismo, la deficiente circulación y los precios de los libros dificultaban su difusión entre la población; Bernabé García se revela como hombre de gran cultura: su biblioteca particular contaba con 94 volúmenes, entre los que predominan los de materia religiosa, Vidas de Santos y de Vírgenes y de la Historia eclesiástica, libros de devoción, libros pastorales, literatura ascética, teología moral y dogmática, sermonarios, etc. A continuación, aparecen obras de materia histórica como la Historia de España del padre Mariana, que revelan su amor a la patria. Entre las obras literarias destacan obras de Quevedo, Mateo Alemán, Gracián, Saavedra Fajardo, contemporáneos del boticario y obras de escritores renacentistas como Hernando del Pulgar, Santa Teresa o Diego de Estella. Finalmente, por su cantidad, aparecen libros de medicina y farmacia, pero también encontramos de aritmética, astronomía o divulgación científica. Las características de la biblioteca nos presentan la personalidad de Bernabé García como tradicional, conservadora y muy marcada por el peso de la religión, como la mayoría de sus contemporáneos (Martín Verdejo, 2004).

\section{Un boticario de pueblo}

Se publicó en Cádiz, a inicios del XIX, una conversación de rebotica entre un boticario de pueblo y el párroco del lugar cuyo tema era la Inquisición. Se tituló Conversación entre el Cura y el Boticario de la villa de Porriño sobre el tribunal de la Inquisición (1812). Este librito, subversivo para la época, llegó a Cataluña donde se reimprimió, lo que muestra el interés crítico de la población por este tema. En esta conversación se ataca, no la religión, que se preserva, sino la institución que se utiliza, en palabras del boticario, para sostener el despotismo y convertir en hipócritas a todos aquellos que se convierten, no por voluntad propia, sino por obligación ante posibles penas y represalias de la institución. Además, sostiene que hasta el siglo XIII, el catolicismo subsistió sin necesidad de este Tribunal y que si en España se conserva la religión ha sido debido a las virtudes de la misma y no a la Inquisición. La posición del cura coincide con la del boticario, a quien aclarará diversos puntos de la doctrina católica: no es a la Inquisición a la que corresponde velar por el catolicismo, son los sacerdotes que están en contacto con los creyentes los que deben velar por su rebaño y atraerlo por la gracia del Espíritu Santo, no por la represión. Su figura, a la que el cura califica de mercenaria y de ladrones, no aparece en las Sagradas Escrituras, por tanto, es una invención humana para controlar al pueblo. Además, se critica la figura de los altos cargos de la Iglesia, uno de los motivos por los cuales se ha llegado a la actual situación: no todos los obispos 
consagrados son obispos en santidad. Todos mandan y desean mandar, pero muy pocos aprovechar. Aún así, serían, junto con los párrocos, los verdaderos veladores de la fe frente a los Inquisidores que habitan en casas que ni palacios, pasean en buenos coches y cuando van a pie, con su lacayo de ostentación. De hecho, el boticario le pone en conocimiento de la huida de unos obispos a Mallorca por ponerse en contra del tirano, abandonando a su rebaño, lo que cuestiona el boticario, cosa que es criticada por el párroco ya que se ha de mirar el fin de la obligación, la salvación del rebaño, no la salvación propia. Acaba el cura defendiendo la separación del poder secular y eclesiástico, que deben actuar en sus respectivas esferas o con sus propios medios, sin mezclar ambos terrenos. En 1814 se publicó una Respuesta familiar a las erradas máximas del cura de Porriño, por el Doctor Don Juan Pablo Constans, Canónigo de la Colegiata de Pons.

\section{Boticarios de ciudad}

En la ciudad tenemos otros ejemplos como el de Joan Ignasi Davi i Garriga (Cornet i Arboix, 1991), de Manresa (†1757), que junto a Vic y Barcelona eran las únicas ciudades que se consideraban como tales, según el censo de Floridablanca (1787). Su caso nos muestra cómo el boticario está involucrado en la política del país, desde el gobierno municipal. Desde muy temprano, pasa a ocupar el cargo de Regidor Perpetuo de la ciudad de Manresa, nombrado por Felipe V, del que era férreo adepto, y su actividad profesional quedará en un segundo plano. Joan Ameller i Mestre (1743-1824), en cambio, boticario de la plaça de la Llana, es el caso contrario, consagrado a su tarea de boticario y después de profesor en la Real Escuela de Cirugía, miembro de la Reial Acadèmia de Ciències Naturals i Arts de Barcelona, colaborando en la obra botánica sobre el macizo de Montserrat, y nombrado también Apotecario Honorario de Cámara de Su Majestad, lo que nos muestra quizás también, sus inclinaciones políticas. En ambos casos, alcanzan cargos de importancia, pero desconocemos su implicación con la religión, aunque en el caso de Davi i Garriga son notables los proyectos relacionados con la Iglesia que llevó a cabo en Manresa, lo que nos hace creer que, como la mayoría de la población del siglo XVIII, era profundamente creyente.

\section{Procesos inquisitoriales a boticarios}

Los procesos inquisitoriales que hacen referencia a boticarios según el archivo PARES y el Catálogo de Procesos del Tribunal de la Santa Inquisición de Barcelona de Blázquez, son 18, distribuidos por delitos y siglos, de la siguiente manera: (1552) Proceso a Jaume Soler por Delito desconocido, (1561) 
Proceso a Jean Deugerme por Sacrilegio, (1571) Proceso a Antoni Magarola por Libros Prohibidos, (1575) Proceso a Miguel Alfonso por Proposiciones, (1586) Proceso a Jimeno de Arbués por Bigamia, (1594) Proceso a Faugier Pons por Luteranismo, (1602) Proceso a Simon Martre por Islamismo, (1617) Proceso a Joan Galli por Fornicario, (1736) Juan Velarde por Proposiciones, (1744) Proceso a Pedro Cayetano Ruíz por Proposiciones, (1748) Proceso a Feliu Torrella por Proposiciones, (1768) Joaquín Ferrer y otros por Sacrilegio, (1796) Proceso a Bernardo Puniet y a León Lalana por Proposiciones, (s. XVIII) Proceso a Nicolás Olmo Emper por Proposiciones y a Antonio Rodríguez Valderrama por Limpieza de sangre, (1800) Proceso a José Meira por Proposiciones, (1819) Luís Sánchez por Proposiciones, (1820) Proceso a José Campos y Campos por Proposiciones, (s. XIX) Vicente Seara por Proposiciones.

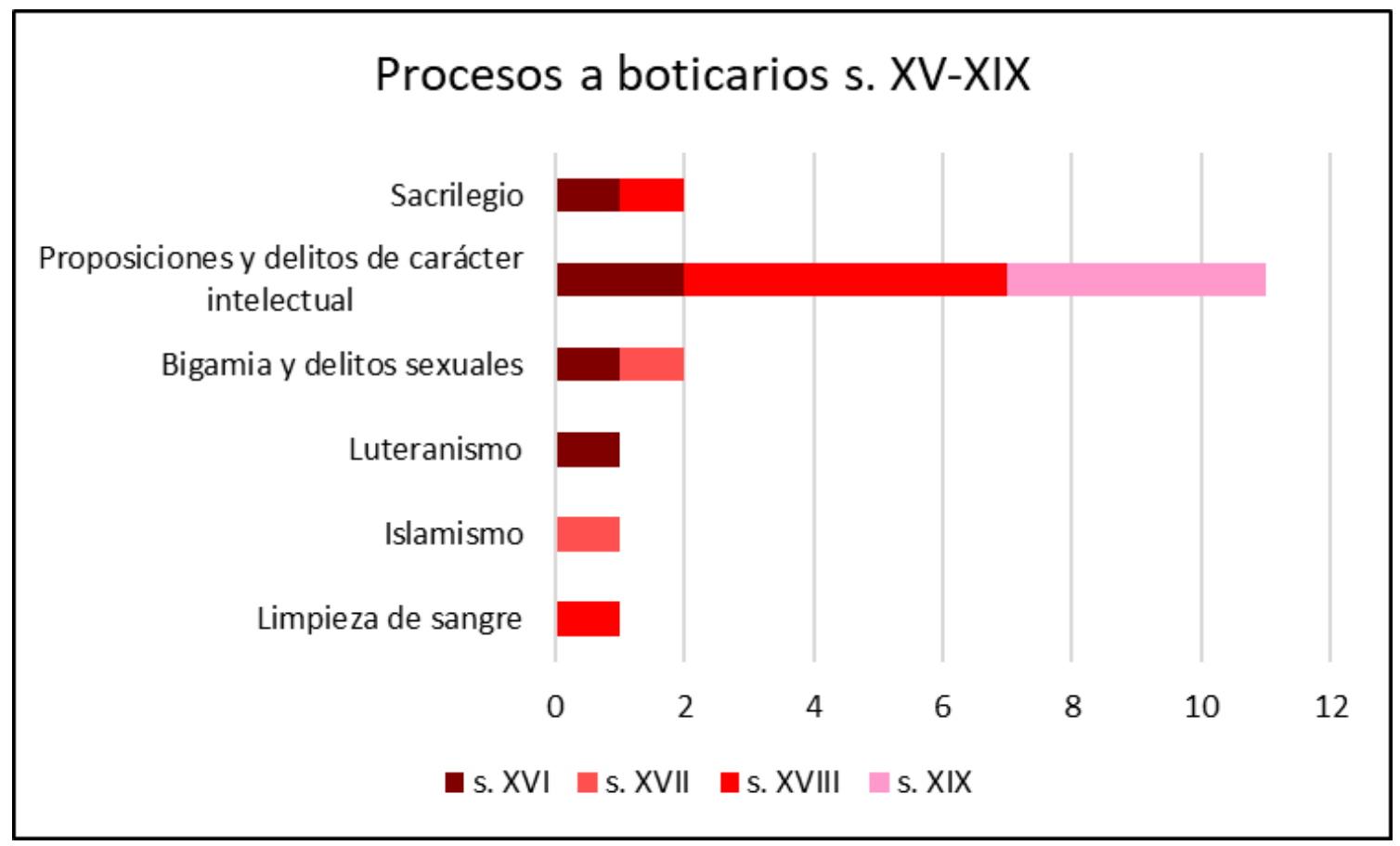

Fig. 1. Procesos a boticarios en los siglos XVI-XVIII en España, extractado a partir de los procesos de PARES y el Catálogo de Procesos del Tribunal de la Santa Inquisición en Barcelona de Blázquez (1990)

Precisamente los delitos procesados a boticarios más comunes son los referentes a proposiciones heréticas, contra le fe católica, no hallándose curiosamente ninguno respecto a la fautoría, contra el Tribunal, aunque ya hemos visto que también existían dudas referentes a su utilidad y su validez cristiana. La mayoría de procesos datan del siglo XVI, etapa en que la Inquisición, tras liberarse de su principal perseguido (en el s. XV), el judeoconverso, se centra en hacer cumplir los preceptos aprobados en el Concilio de Trento, centrándose, en el siglo XVIII, en los delitos de carácter herético intelectual: proposiciones de fe, luteranismo o posesión de libros 
prohibidos y en delitos de tipo sexual, que podían contaminar a la población sumisa y creyente a pies juntillas.

Los delitos por proposiciones se clasificaban en proposiciones heréticas, contrarias a la fe católica. Proposiciones erróneas, contrarias a cualquier verdad no precisada por la Iglesia o al menos no revelada a todos. Proposiciones malsonantes, aquellas que tenían un doble sentido, uno católico y otro herético y que cuando se exponían eran recibidas mayormente en este último. Proposiciones cismáticas, aquellas que atacaban a la unidad de la Iglesia. Proposiciones impías, contra la piedad católica. Proposiciones temerarias, aquellas que no se atenían a las normas de la razón en asuntos tocantes a la fe o a la moral. Proposiciones injuriosas, que difamaban a las autoridades eclesiásticas y proposiciones blasfemas, en que se blasfemaba a Dios.

\section{Procesos inquisitoriales (s. XVIII)}

El proceso a Juan Velarde (1736), mancebo de boticario, en Madrid, se inicia con la delación de Antonio Pemán, servidor de esa casa, que lo denuncia por proposiciones heréticas en las que afirmaba que no se debía la misma veneración a las imágenes de Jesucristo, la Virgen María y los santos que a los que estaban en el Cielo, ni a la imagen de Jesucristo crucificado, la misma que a la del Santísimo Sacramento; rechazando también la figura del Papa y sus atribuciones. El joven se excusa diciendo que él proviene de Francia y el catecismo que allí le enseñan es diferente del de España, se le declara sospechoso vehemente in fide.

En Francia, en el año 1669, un edicto real castigaba a los hugonotes con galeras para los hombres, prisión para las mujeres, y la confiscación de todos sus bienes. A partir de 1682, la prohibición se extiende a los nuevos conversos, con lo que entre 1685 y 1715, se calcula que emigraron unos 200.000 hugonotes. Según Voltaire, la persecución a los protestantes privó a su reino de más de un millón de trabajadores que pertenecían en su mayor parte a la producción artesanal e industrial, los profesionales liberales, al ejército y a la enseñanza, ralentizando el desarrollo del país.

Uno de ellos, probablemente, fue Juan Velarde. Este caso, a pesar de hacer referencia a un trabajador de la botica, se debe a la educación hugonote proveniente del país vecino que recibió el joven y no a una evolución de las ideas entre los boticarios españoles debido a la Ilustración, por lo que no es demasiado representativa de la influencia del pensamiento ilustrado en su opinión sobre la religión o la Inquisición. 
El proceso a Pedro Cayetano Ruíz, fue llevado a cabo por el Tribunal de Llerena en el año 1744, tiene una botica en Monte Hermoso y es originario de Monforte de Lemos (Galicia). Es denunciado por carta por Joseph Tovar al oírle decir que el alma racional no podía padecer siendo espiritual y que no había infierno, que solo aparente y que no era así lo que decían los predicadores, porque solo era para aterrar. También se le acusa de ser hijo de médico judío y de no acudir a misa los días de fiesta y cuando la oye es con mucha irreverencia, con el gorro puesto y sin hacer genuflexión al alzar a Dios. Un criado le acusa de no dar gracias a Dios en la mesa y que cuando se lo reconvino, el boticario respondió que eso era brujería. Otra criada le acusa de no dejarla ir a misa con el pretexto de que tenía que ayudarle a preparar medicinas; también refiere que tildaba las procesiones de gazmoñería y que se podía rezar a solas, aunque nunca se le vio coger el rosario. Además se le acusa de intentar matar a Tovar por delatarle. Se da cuenta al Tribunal de Santiago sobre el reo para conocer sus orígenes judíos, que le confirman la nota pública de judío y su relación con una mujer portuguesa, conocida como la Beata, con la que tuvo varios hijos naturales sin casarse. Ante una estancia en la cárcel por ese motivo, él lo justifica diciendo que sigue la ley de Catón.

Respecto al ejercicio de sus funciones como boticario, se le acusa de vender medicinas para provocar el aborto, cosa por la cual ya había sido castigado Se le acusa también indirectamente de sortilegios o bebidas amatorias porque se alude a una bebida que le dio el acusado a un hombre para que nunca se separase de la mujer con la que estaba amancebado, conociendo este hecho, otra mujer acude a la mujer amancebada para que le dé el remedio para que su amante no la deje, a lo que esta le responde que acuda al boticario pero que antes le pedirá conocerla carnalmente. No obstante, cuando estas mujeres son citadas a declarar, niegan los hechos. Por otra parte, se le acusa de curar los lamparones ${ }^{4}$ refregándose con la mano de un muerto antes de que se enfriara.

Se le acusa pues, de proposiciones heréticas, erróneas y escandalosas, se le califica de atheista y hereje judaizante. No aparece el castigo que se le da en el proceso.

En este caso confluyen numerosos datos, primero su ascendencia judía, a pesar de la cual había podido establecer una botica, lo que muestra que los gremios o bien no eran tan estrictos en sus demandas del certificado de limpieza de sangre, o bien el acusado tenía conocidos que le permitieron librarse de este requisito. Segundo, su desprecio hacia la religión. El boticario, además de ser cristiano viejo, debía cumplir con la tradición y ser un buen cristiano y de buenas costumbres, parece ser que Pedro Cayetano Ruíz, tenía ideas muy interesantes sobre la religión que hacen que lo califiquen de ateísta y no cumplía con ese patrón. Quizás la influencia del pensamiento ilustrado,

\footnotetext{
${ }^{4}$ Paperas, escrófulas.
} 
anticristiano y antirreligioso da lugar a un hombre que por su tipo de vida y su afirmación del alma racional abrigó un sentimiento religioso libre de dogmas y ritos. Desconocemos muchos aspectos de su vida, pero su posición ante el aborto y la expresión de que se puede rezar a solas, sin los ritos de los que hablábamos, o su afirmación de que el infierno existe para aterrarnos, muestran un espíritu crítico y libre, consciente de la influencia de la religión en la sociedad. Una sociedad basada en la religión para controlar al pueblo.

El historiador francés Flandrin emitió la hipótesis, de que en el Antiguo Régimen existieron dos tipos de comportamientos sexuales; uno conyugal, que respetaba las prohibiciones hacia las prácticas contraceptivas (regulando naturalmente la concepción con el matrimonio tardío y el largo amamantamiento) y otro extraconyugal que sería el que utilizaría la contracepción y más concretamente el aborto. Afirmó que sería en este sector marginal en el que las mujeres, pocas en realidad, recurrirían al aborto de los niños ilegítimos, a pesar de los riesgos mortales de semejante práctica. De cualquier forma, la represión hacia el aborto es muy criticada en el siglo de Las Luces, Beccaria, por ejemplo, abogó para que la mujer que abortara adquiriera el estatuto de víctima, ya que arriesgaba su vida para salvar su honor. El Código Penal francés de 1791 no prevé penas para la mujer que abortaba, aunque sí para quien se lo provocaba (Flandrin, 1984).

Por otra parte, las referencias a los bebedizos amatorios o a la curación de los lamparones en la práctica de su profesión nos muestran un aspecto del boticario más propio de curanderos o brujas, más arraigado a la superstición, lejano a la razón, que no coincide con la descripción anterior que hemos dado de él. La Ilustración es en España una etapa de luces y sombras, como su arte, Goya, nos muestra también; en el que la razón y la superstición se mezclan dando lugar a personajes como el descrito.

El proceso a Feliu Torrella se da en Barcelona en el 1748. Tiene botica en San Hipòlit de Voltregà, ha estudiado Gramática y Filosofía, pero no se dice nada sobre los estudios que debió realizar para acceder a los exámenes de boticario. Es delatado por Joseph Vall, religioso mercenario de 31 años, que es testigo de haber oído acusaciones de la mujer del médico de lugar que afirma haber oído decir al boticario que se salvaban los que fornican y los que hurtan y que tanta culpa tenía Dios como él mismo, también lo acusan de que haría cualquier cosa por ganar dinero. Se le califica de lujurioso, afirma que, ya que eran permitidas las rameras, era lícito copular con ellas; colérico y codicioso, en una conversación comenta uno de los testigos, un cirujano, que hablaron de sus oficios y de que Dios reparte las riquezas según su voluntad, a lo que él respondió que desde ese punto de vista para él Dios era un pequeño trapito y que hacía parcialidades en esta distribución. 
Además, se refiere a Dios como Aquell camas de aranya o anca d'ametlla, lo cual constituía una blasfemia, junto con otras aseveraciones sobre el Antiguo y Nuevo Testamento que reconoce haber dicho y que establece como imposibles porque le aturden por su falta de veracidad, por no poder ser acordes con la naturaleza racional de las cosas, como que la ballena tragó a Jonás, lo que no podría ser por lo angosto de la garganta. Tras los testimonios presentados, él mismo hace una confesión espontánea ante el Santo Oficio, aconsejado por el médico Juan de Besta, se retracta de algunas de sus opiniones sobre la fornicación y sus blasfemias, califica de falsas algunas de las acusaciones como la del uso de las rameras, se declara cristiano viejo, asegura que se ha confesado y ha comulgado en los últimos 30 días. Se le calificó de hereje formal por proposiciones temerarias, escandalosas, erróneas, injuriosas y blasfemas y sospechoso de levi, con cárcel y secuestro de bienes hasta el veredicto final.

A diferencia de Pedro Cayetano Ruíz, aunque parece que veamos actitudes similares; el primero parece hacer una reflexión sobre la doctrina y la rechaza de pleno; el segundo, en cambio, a pesar de expresar un pensamiento crítico hacia la religión, también la utiliza para justificar sus acciones. Al mismo tiempo la rechaza y la hace responsable de las acciones cometidas. Quizás exista una cierta influencia calvinista o hugonota interpretada desde la óptica más conveniente a su estilo de vida, en que, independientemente de lo que uno haga, Dios ya ha predeterminado si este se salvará o no, por tanto, no hace falta creer. Los calvinistas, en cambio, también creían que: puesto que obrar y vivir en el temor de Dios se interpreta como síntoma de que se es uno de los pocos elegidos, todos deseaban descubrir en sí mismos los signos de la gracia divina y obraban convenientemente (Schwanitz, 2002).

Bernardo Puniet (1796) de Vilanova i la Geltrú, es denunciado por Josefa Rafecas y Alegret sobre varios comentarios que lanzó, a propósito de la muerte de un convecino. Las sentencias se repiten: no existe infierno, los santos solo son pedazos de lienzo y no existen demonios, son las proposiciones de las que se le acusa.

A León Lalana (1796) de Zaragoza, lo denuncia Miguel Ibáñez, escribano, por recomendación de su párroco. Parece ser que en una reunión con varias personas comentó que los mandamientos de la Iglesia se debían quitar y que también los sacramentos, se debían reformar porque los sacerdotes los vendían. Se le consideraba un hombre que tendía a disparates y ocioso porque su padre era el que llevaba la botica. Se le castiga por proposiciones temerarias, escandalosas y erróneas, injurias a los miembros de la Iglesia y al Rey, ya que, aunque no se especifica exactamente, también se queja del estado. 
Las quejas de León Lalana se refieren fundamentalmente a cuestiones económicas relacionadas con la Iglesia y el Estado. Los ingresos propios de la actividad religiosa eran los diezmos y las primicias, ofrendas y limosnas, donaciones y herencias. A estos se añadían los derechos de estola, es decir las retribuciones que los fieles daban a su cura por las funciones sacerdotales durante las cuales llevaba la estola, especialmente en los casamientos, los bautismos, los entierros, etc. En su origen eran donativos voluntarios, en materia o en dinero, que los fieles daban por reconocimiento a su párroco. La Iglesia siempre ha mantenido el principio de que los Sacramentos deben distribuirse gratuitamente, y condena como simonía todo pago de una función eclesiástica. Sin embargo, permitía el cobro de sus servicios, siempre y cuando no se marginara a la población pobre y también pudiera tener acceso al sacramento gratuitamente. Poco a poco estos donativos espontáneos llegaron a ser de una observancia regular y considerados como un suplemento necesario y obligatorio para el mantenimiento de los curas de las parroquias. Así, tenemos el ejemplo de la parroquia de Morales del Rey: por cada bautizado se daba al cura 4 reales, una polla, medio azumbre de vino y una torta; por cada matrimonio se daba al cura quince reales; por un funeral dos reales, siete hogazas de seis libras cada una, siete carillas y medio azumbre de vino a parte los derechos de sepultura, que dependían del lugar donde eras enterrado ${ }^{5}$. Teniendo en cuenta que el sueldo medio de un labrador en el siglo XVIII era de 5 reales/día y el de un jornalero 2 reales/día, podían quedarse sin comer perfectamente de un día a una semana para llevar a cabo el pago de los sacramentos. Lalana denuncia, quizás influido por las ideas de su tiempo, la corrupción de la Iglesia católica como había pasado en tiempos de la Reforma.

Finalmente, el caso de Nicolás Olmo, procesado por el Tribunal de Cuenca, María Antonia López, llamada la Beata, lo denuncia por haber dicho que el alma de Cristo era la misma divinidad y que Dios no creó el alma de Cristo y que se cagaba en la Santísima Trinidad. Se le calificó como hereje con influencias de arrianismo y apolinarismo. No se le condena ya que se considera que actuó por ignorancia y se suspende la causa.

En una época como la Ilustración, aunque empezaban a llegar atisbos de la razón, la Iglesia todavía constituía una de las partes más importantes de la sociedad, la sociedad moderna era una sociedad sacralizada y hablar sobre asuntos cristianos era común, más aún en personas con espíritu crítico que intentaban comprender los fundamentos de la misma y racionalizarlos. En este caso el problema aparece cuando se pretende debatir un concepto teológico que es un misterio para la propia Iglesia y que solo se entiende a través de la fe. Las interpretaciones personales del catecismo pueden 
conducir a ello y desembocar en lo que la Iglesia consideraba errores como el arrianismo que es una creencia cristiana no trinitaria. Afirma que Jesucristo fue creado por Dios Padre y está subordinado a él. Las enseñanzas arrianas fueron atribuidas a Arrio, 250-335 d. C., y se oponen a las llamadas ortodoxas acerca de la naturaleza divina. Por otra parte, la doctrina de Apolinar de Laodicea surgió en respuesta a la arriana y también fue condenada por la Iglesia. Afirmaba, por el contrario, que en Cristo no existía un alma humana. Nicolás Olmo interpreta las palabras del catecismo desde esta óptica hereje para la Iglesia católica.

Encontramos, como acusado de sacrilegio a Joaquín Ferrer (1768), boticario de Lasquarre, Huesca, procesado por el tribunal de Zaragoza por celebrar el entierro del Carnaval disfrazado de presbítero, acompañado de otros amigos disfrazados de diácono y subdiácono, con una cruz hecha con cañas, y dos amigos más disfrazados de enterradores con azadas yendo a la plaza donde tenían una sepultura, simulando un entierro, imitando toda la ceremonia de la Iglesia. El acusado refiere estudios de Gramática y aprender el oficio de boticario con su tío. Son acusados de sacrilegio y encarcelados con secuestro de bienes. Aún en la Ilustración, el poder de la Iglesia en España era tan grande que no se permitía ni el menor ridículo a la misma, ya que podría poner en peligro su autoridad, ni en fechas como las Carnestolendas (16 de febrero), que nombran de origen en el proceso, se permite la burla o el escarnio a la institución.

\section{Conclusiones}

La postura del boticario ante la Inquisición no difiere en la de otros ciudadanos, quizás sus delitos, principalmente de proposiciones, nos muestren un mayor espíritu crítico que el resto de sus conciudadanos debido a su cultura. Otro estamento social que presenta gran número de casos, el mayor, por proposiciones son los religiosos, que dudan de la fe estudiada y practicada, y los soldados, especialmente de origen extranjero que conservan su religión de origen o por influencias de los países y los compañeros de otras nacionalidades con los que han coincidido. Sin embargo, los sastres del XVIII, quizás con menor acceso a la cultura, también presentan un mayor número de casos por proposiciones en este siglo, la razón en España despertaba y se extendía entre la población. Todo ello nos lleva a pensar: ¿Era influencia de la Ilustración? Las nuevas ideas ilustradas llegaron a España por diversas vías, pero, por otra parte, la decadencia de la España del siglo XVII que pasó de Imperio hegemónico a uno de los países más empobrecidos de Europa, que veía como países no católicos progresaban a un ritmo que la leyenda rosa ya no podía defender, había, probablemente, despertado en los españoles el sentimiento de crítica hacia el catolicismo. 
Respecto al ejercicio de la profesión farmacéutica, se refiere en dos de los casos los estudios de Gramática y en uno de ellos, también de Filosofía, pero en ningún momento se hace referencia a sus estudios de boticario. En el siglo XVIII, los exámenes de acceso al oficio hacían necesario el estudio de la botánica y de la química, ya existían los primeros tratados sobre estos temas de las manos de Linneo y Lavoisier, pero también de otros autores que los adaptaban al estudio del oficio. Ello nos da que pensar, si realmente todos los boticarios pasaban ese examen o solo con el aprendizaje, que todos ellos refieren en la botica, era suficiente para ejercer.

Por otra parte, dejando a un lado la publicación de Porriños, observamos que una institución como la Inquisición, fácilmente criticable, es respetada en todo momento por los procesados. No existen delitos de fautoría, probablemente por el respeto que generaba la institución.

En cambio, la fe católica sí es cuestionada desde diferentes aspectos. Así, encontramos tres posturas frente a la Inquisición y/o la fe católica, los que la aceptaban sin mayor reflexión, dedicados a su botica y a su negocio o a sus aspiraciones políticas o académicas; los que cuestionaban su existencia como el caso explicado de Porriños, y los que negaban la propia fe, por influencia de la razón que empezaba a despertar entre la población.

\section{Referencias bibliográficas}

CALLEJA, MC.(1992) La farmacia en la Ilustración, AKAL, Barcelona.

Conversación entre el Cura y el Boticario de la villa de Porriño sobre el tribunal de la Inquisición, Cádiz, 1812.

CORNET I ARBOIX, Ramon (1991), «Joan Ignasi Davi i Garriga: apotecari i botifler», Gimbernat, 15, pp. 89-97.

ESTEVA DE SAGRERA, Juan (2007) «La farmacia del siglo XVIII». Offarm, 26, pp.118-22.

FLANDRIN, Jean Louis, La moral sexual en Occidente, 1984.

MARTÍN VERDEJO, Félix (2004) «La vida y la biblioteca de Bernabé García, boticario rural del siglo XVIII», Asclepio-Vol. LVI-2.

MESTRE, Antonio; PÉREZ GARCÍA, Pablo (2004). «La cultura en el siglo XVIII español». En Luis Gil Fernández y otros. La cultura española en la Edad Moderna. Historia de España XV. Madrid. PALMERO RAMOS, Rafael (1989) «Vida religiosa. Usos y costumbres de Morales del Rey en el siglo XVIII». https://dialnet.unirioja.es/descarga/articulo/1401646.pdf,. 
PUERTO SARMIENTO, Francisco Javier (1992) «Ciencia y Farmacia en la España decimonónica», AYER, 7, pp. 153-191.

RODRÍGUEZ SÁNCHEZ, Rafael Angel (2008) «La evolución de la concepción de enfermedad en John Locke: el galenismo y la iatroquímica» Thémata. Revista De Filosofía. Núm. 40, pp. 97-115. SCHWANITZ, Dietrich (2002) La cultura. Todo lo que hay que saber, Taurus, Madrid. URREIZTIETA, José Luis (1985) En Las tertulias de la Rebotica en España (Siglo XVIII-XX), Alonso, Madrid.

ZARZOSO, Alfonso (1996) «Protomedicato y boticarios en la Barcelona del siglo XVIII», DYNAMIS. Acta Hisp. Med. Sci. Hist. Illus. 16, pp. 151-171.

\section{Fuentes primarias}

Proceso de fe de Diego de Cáceres, INQUISICIÓN, 119, Exp.14 - 4, AHN.

Proceso de fe de Antonio Rodríguez Valderrama, INQUISICIÓN, 3734, Exp.240, AHN.

Proceso a Juan Velarde, INQUISICIÓN, 3736, Exp.64, AHN

Proceso a Pedro Cayetano Ruiz, INQUISICIÓN, 3734, Exp.50, AHN.

Proceso a Feliu Torrella, INQUISICIÓN, 3724, Exp.108, AHN.

Proceso a Bernardo Puniet, INQUISICIÓN, 3731, Exp.6, AHN.

Proceso a León Lalana, INQUISICIÓN, 3730, Exp.247, AHN.

Proceso a Nicolás Olmo, INQUISICIÓN, 3722, Exp.223, AHN.

Proceso a Joaquín Ferrer, INQUISICIÓN,3732, Exp.438, AHN.

\section{Webgrafía}

http://www.congreso.gob.pe/Docs/participacion/museo/Inquisicion/files/delitos-juzgados1.pdf Musée virtuel du protestantisme français. «La pratique religieuse du Désert» Consultados junio 2018. 